\title{
EDUCACIÓN Y DESARROLLO SOCIO-ECONÓMICO
}

\author{
Francisco Miguel Martínez-Rodríguez \\ Universidad de Granada \\ Luis V. Amador Muñoz \\ Universidad Pablo de Olavide (Sevilla)
}

\begin{abstract}
RESUMEN: En el presente trabajo analizamos críticamente la noción de desarrollo desde una perspectiva socio-histórica. Comprobamos que este concepto no es sólo sinónimo de crecimiento económico, sino que más bien se trata de un término interdisciplinar en el que además se interrelacionan los aspectos educativos, sociales, políticos, culturales, etc. Asimismo, y después de analizar la realidad socioeconómica actual, Ilegamos a la conclusión de que es preciso orientarnos hacia un nuevo modelo de crecimiento, centrado en nuestro caso en el fomento de la cultura emprendedora, donde la educación deje de tener un valor exclusivamente instrumental al servicio de los intereses económicos de unos "pocos privilegiados" y se convierta en el motor de un desarroIlo humano capaz de favorecer el progreso, la igualdad y la justicia social.
\end{abstract}

ABSTRACT: In this paper we perform a critical analysis of the notion of development from a socio-historic viewpoint. We find that this concept is not only synonymous with economic growth, but rather is an interdisciplinary term in which educational, social, political and cultural aspects also interrelate. Moreover, having analysed the current socioeconomic situation, we conclude that it is time to move towards a new growth model, in our case focusing on fostering an entrepreneurial culture, where education ceases to have a purely instrumental value to serve the interests of a "privileged few" and becomes the driving force for human development with progress, equality and social justice.

PALABRAS CLAVE: Educación, desarrollo, crecimiento socioeconómico, cultura emprendedora, redistribución de la riqueza, justicia social.

KEYWORDS: Education, development, socio-economic growth, entrepreneurial culture, redistribution of wealth, social justice.

\section{INTRODUCCIÓN}

El concepto de "desarrollo" ha sido objeto de estudio de numerosos investigadores sobre todo a partir de la Segunda Guerra Mundial, convirtiéndose en los últi- 
mos 60 años en un elemento central de las políticas económicas de los Estados. Se trata de un término que ha estado tradicionalmente ligado al de "crecimiento económico" y, a partir de la década de los 70 del pasado siglo XX, al de "educación" por medio del "enfoque del capital humano" (Schultz, 1963; Becker, 1983).

En la actualidad se hace necesario revisar dicho concepto, máxime en un contexto de crisis económica a escala planetaria en el que además se están generalizando las situaciones de pobreza y marginación. En este sentido, hemos estructurado el presente trabajo en tres grandes apartados. En primer lugar, analizamos críticamente la noción de desarrollo desde una perspectiva socio-histórica, desde su origen con el proceso de Revolución Industrial a mediados del siglo XIX hasta la actualidad. En este recorrido observamos que dicho término no se puede entender exclusivamente como sinónimo de crecimiento económico, sino que más bien se trata de un término interdisciplinar en el que se interrelacionan los aspectos educativos, sociales, políticos, culturales, etc., además de los económicos.

En segundo lugar, Ilegamos a la conclusión de que es necesario redefinir nuevamente el concepto de desarrollo, pues a pesar de que se han producido avances importantes en este sentido al menos a nivel teórico, lo cierto es que las desigualdades sociales y económicas no paran de aumentar inclusive dentro de los países denominados a sí mismos desarrollados. La educación juega un papel decisivo en todo este proceso, ya que puede ayudarnos a concienciar sobre la necesidad de reconducir los patrones de crecimiento y desarrollo sobre los principios de sostenibilidad, equidad y compromiso social dejando a un lado los clásicos criterios economicistas, materialistas y tremendamente individualistas que han caracterizado tradicionalmente dicho concepto.

Por último, defendemos que es preciso orientarnos hacia un nuevo modelo de crecimiento, centrado en nuestro caso en el fomento de la cultura emprendedora, donde la educación deje de tener un valor exclusivamente instrumental al servicio de los intereses económicos de unos "pocos privilegiados" y se convierta en el motor de un desarrollo humano capaz de favorecer el progreso, la igualdad y la justicia social. Debemos pasar de un modelo que privilegia la ideología individualista por encima de todo, a un nuevo modelo que fomente la participación de todos los ciudadanos bajo la premisa de la responsabilidad social. Así pues, los diferentes agentes sociales y educativos debemos abogar por una educación que promueva la solidaridad como nuevo valor social contribuyendo con ello a la redistribución de la riqueza.

\section{ACERCA de la NOCIÓN DE "DeSARROllO": PeRSPECTIVA SOCIO-HISTÓRICA}

Desde una perspectiva histórica la noción de "desarrollo" de un país o región está necesariamente unida al proceso de Revolución Industrial (Brunet y Böcker, 2007). Este proceso configuró como modelo de crecimiento económico al sector industrial, concebido como fuente de progreso y, por consiguiente, como motor de desarrollo económico. Desarrollo y crecimiento económico se convierten a partir de mediados del siglo XIX en términos inseparables, hasta el punto de vincular el desa- 
rrollo con una mayor industrialización que daría lugar a un incremento de la producción o, lo que es lo mismo, al crecimiento económico.

En este orden de cosas, desde la Primera Revolución Industrial se ha asociado la revolución tecnológica con desarrollo económico. Así por ejemplo, con el avance de la tecnología se pasa, en la segunda mitad del siglo XIX, de una sociedad básicamente agraria y rural a una industrial "avanzada". Por ello, bajo esta concepción determinista de la tecnología aparece con fuerza la empresa industrial privada.

Este contexto de incipientes Estados-nación y de la lógica del capitalismo industrial, escenario de los grandes imperialismos europeos, tiene como notas características el ansia de poder y de riqueza por parte de estos Estados denominados a sí mismos "civilizados", en donde el desarrollo tecnológico e industrial implica desarrollo económico.

A este respecto Herbert Marcuse (1984) señaló que la fórmula del capitalismo industrial produjo, además de la clásica división del trabajo, unas relaciones de intercambio entre los imperios y las colonias desiguales, así como el sometimiento de la clase obrera-trabajadora a los intereses de los patronos industriales. Esto dio lugar a unos niveles de crecimiento diferenciados entre unos países y otros, aumentando con ello las desigualdades y la brecha económica entre los más industrializados (Estados nacionales capitalistas) y los más "subdesarrollados" según esta visión tecnicista. Produciéndose una concentración del poder y la riqueza material en los denominados imperios.

El liberalismo económico se convierte en el centro de atención de las teorías económicas clásicas emanadas tras el proceso de industrialización, en donde el valor del individualismo extremo ocupa un lugar central. El desarrollo, como sostiene George (2008), es medido en términos de "progreso de la civilización". Así pues, las sociedades eran clasificadas según unos estadios de desarrollo lo que permitía justificar y legitimar el expolio por parte de las naciones denominadas desarrolladas a los vencidos y colonizados.

Este grado de desarrollo se medía en función del nivel de industrialización, lo que les confería el calificativo de "sociedades civilizadas". En este sentido, desde el siglo XVIII hasta prácticamente la Segunda Guerra Mundial, desarrollo es sinónimo de civilización (Brunet y Böcker, 2007). Se aplica la concepción evolucionista del desarroIlo surgida en las ciencias naturales a finales del XVIII, inspirada en los estudios de evolucionistas como Darwin, al terreno social. Por lo que se habla de "evolucionismo social" para explicar el "grado de desarrollo" de unas sociedades con otras.

No se tenían en cuenta a la hora de señalar el nivel de desarrollo de un país aspectos tales como: el grado de solidaridad entre los diferentes grupos sociales, el apoyo mutuo orientado al bien común, la responsabilidad social, la tolerancia y el respeto mutuo, la paz social, el trabajo en equipo, el compromiso social, etc.; sino que el desarrollo era concebido simplemente como sinónimo de mayor tecnificación e industrialización. No importaban las condiciones de vida de los trabajadores industriales ni la explotación a la que se veían sometidos, tan sólo se pensaba en aumentar la productividad.

Por este motivo, es razonable pensar que autores como Comte, Spencer, Durkheim o Smith (Samuelson y Nordhaus, 2006), entre otros muchos, consideraran que 
el nuevo motor de desarrollo económico en la denominada "primera globalización" (1870-1913) estaba motivado por el sector productivo industrial, Ilegando a argumentar que el capitalismo competitivo que sustentaba dicho modelo de desarrollo era el mejor de todos los sistemas económicos posibles hasta la fecha. Lo cual dejaba claramente a un lado los aspectos humanos y sociales del desarrollo a favor de los más técnicos y materiales. No sólo esta visión del desarrollo de finales del XIX y principios de XX ha contribuido a aumentar las desigualdades sociales como es de sobra conocido, sino que además se ha puesto en evidencia la falta de autorregulación por parte del sistema económico y la supuesta redistribución de la riqueza de la que hacían gala.

Podemos observar aquí la ambivalencia de la palabra "desarrollo" de la que hablaba Roger Ciurana (2001), ya presente en estas primeras etapas del capitalismo industrial, ya que por un lado se habla de "desarrollo material" entendido como desarrollo tecnológico, científico y económico que históricamente ha ido provocando un gran costo en degradación ecosistémica. Y por otro lado, el autor nos habla también del "desarrollo mental" como la parte subdesarrollada del desarrollo, pues ambos desarrollos: el material y el mental no han ido tradicionalmente unidos.

En este sentido, los economistas clásicos fueron extendiendo el "pensamiento único" o, lo que Roger (2001: 11) denomina "el mito tecnoeconómico", es decir, la falsa creencia de que a mayor industrialización las sociedades alcanzan mayores niveles de bienestar reduciéndose con ello las desigualdades sociales. Sin embargo, una mirada crítica y retrospectiva a nuestro pasado más cercano nos indica todo lo contrario y es que no han parado de aumentar los desequilibrios sociales a medida que aumentaba el desarrollo material.

No obstante, la "crisis del 29" restó credibilidad a estas corrientes económicas clásicas (Navarro, 2008), pues se puso en evidencia, entre otros aspectos, el supuesto equilibrio de los sistemas económicos. Este hecho, unido a la grave situación económica y humanitaria que caracterizó a la práctica totalidad de la sociedad occidental tras la Segunda Guerra Mundial, provocó un marcado interés por el proteccionismo y el intervencionismo del Estado en los asuntos económicos.

Se lleva a cabo un ambicioso proceso de reestructuración económica liderado por Estados Unidos con el conocido "Plan Marshall" firmado en 1947, con el que se pretende la reestructuración económica de Europa bajo nuevas políticas económicas inspiradas en los principios keynesianos. Azqueta y Sotelsek (2007) sostienen que es en este contexto de postguerra donde las grandes "teorías del desarrollo económico" tienen su origen.

Para Brunet y Böcker (2007) fue el economista británico John Maynard Keynes quien sentó las bases de las teorías del desarrollo económico tras la II Guerra Mundial. Estas teorías promovieron la innovación industrial y la ideología industrializadora, rechazando la idea anterior de un mercado autorregulado. Nos estamos refiriendo a las cuatro grandes teorías que intentan explicar el proceso de desarrollo a partir de mediados del XX: "Economía del Desarrollo", "Los Modelos de Acumulación Acelerada: El Modelo Soviético de Industrialización", "La Escuela Estructuralista de la CEPAL" y "Las Teorías de la Dependencia". 
Como indicábamos, estas teorías del desarrollo se nutren de la obra de Keynes e introducen cambios importantes no contemplados hasta la fecha: se aboga por un mayor intervencionismo por parte del Estado en los asuntos económicos, se rechaza por tanto que los agentes económicos fuesen racionales y que los mercados se equilibrasen por sí mismos, al tiempo que se mejoraban los desequilibrios del mercado corrigiendo los fallos del libre funcionamiento de los mismos.

Por lo tanto, la nota destacada de las teorías del desarrollo económico de postguerra, que se extendieron desde los años cincuenta hasta la década de los setenta del pasado siglo, es el mayor intervencionismo por parte del Estado para, de alguna manera, corregir los desequilibrios sociales y económicos que había provocado el mercado, ya que entre otras funciones se encargaría de gestionarlo.

La noción de "desarrollo" va a dar un giro importante a partir de 1950, orientando las políticas nacionales y dando lugar a la "economía del desarrollo". Asimismo, aparece el término "subdesarrollo" para referirse a las regiones económicamente más atrasadas. La noción de desarrollo pierde su tradicional concepción y deja de significar "progreso de la civilización" y se vincula al incremento de la riqueza. El subdesarrollo ya no se utiliza para referir aquellas regiones o países "primitivos o poco civilizados", sino que se entiende como ausencia de desarrollo, como ausencia de riqueza (Brunet y Böcker, 2007).

Sin embargo, como defienden Azqueta y Sotelsek (2007) estas cuatro grandes teorías no alcanzan su ambicioso objetivo: el desarrollo. Por lo que a mediados de los años 70 del siglo XX son rechazados los modelos teóricos que respaldaban dichas teorías. El motivo principal del rechazo tuvo que ver con las condiciones de vida de la población, ya que éstas no mejoraban. Además entraron en escena otros problemas no contemplados hasta entonces como eran: el paro y el desempleo, la pobreza, la marginación o la exclusión social.

Así pues, a partir de 1970 podemos decir que se inicia la "Segunda Década del Desarrollo", según la Asamblea General de las Naciones Unidas (Samuelson y Nordhaus, 2006; Azqueta y Sotelsek, 2007; Brunet y Böcker, 2007), en donde el concepto de "desarrollo" ya no es visto simplemente como sinónimo del crecimiento económico, aunque éste sigue ocupando un lugar central, sino que ahora se tienen en cuenta otro tipo de aspectos de tipo social, educativo, etc. Podríamos decir que el centro de atención de las nuevas políticas del desarrollo se orienta hacia la satisfacción de las necesidades básicas y al crecimiento con equidad.

\section{REDEFINIENDO EL CONCEPTO DE DESARROLLO: IMPLICACIONES EDUCATIVAS Y CULTURALES}

El término desarrollo comienza a redefinirse bajo otros parámetros no exclusivamente economicistas. A ello contribuyen, en cierto modo, los grandes organismos e instituciones internacionales creados a mediados de los cincuenta como es el caso del Fondo Monetario Internacional (FMI) o el Banco Mundial (BM), que además de abogar por el crecimiento continuado del Producto Interior Bruto (PIB) de todos los seres humanos y por aumentar la riqueza de los llamados "subdesarrollados", defienden la importancia de otros factores claves para el desarrollo como son: exten- 
der la educación obligatoria y la alfabetización a toda la población mundial, mejorar la sanidad, las condiciones de vida, erradicar la pobreza extrema, etc. (Varela y Varela, 2002).

Aparece así la necesidad, a partir de los 70, de concebir el desarrollo bajo otro prisma diferente. Desde esta perspectiva, Michael Todaro (1982) establece en el último tercio del siglo XX que la noción de desarrollo fue redefinida en términos de reducción y eliminación de la pobreza, la desigualdad y el desempleo, eso sí, todo dentro de un contexto que seguía abogando además por el crecimiento económico.

Se presenta una visión interdisciplinar del crecimiento como consecuencia de esta revisión del desarrollo en la que se van a tener en cuenta, al menos a nivel teórico, además de los aspectos económicos, los educativos, sociales, políticos, etc. Ahora se habla de "desarrollo social" como un nuevo modelo de crecimiento redistributivo. Una nueva visión que se aleja de las clásicas tendencias economicistas anteriores y se centra en problemáticas que no habían tenido antes en cuenta los economistas para explicar el crecimiento económico de un país.

Nos estamos refiriendo a problemáticas como la pobreza, la educación, la desigualdad, la vivienda, el desempleo, la sanidad, el medio ambiente, etc. , en definitiva, de lo que se trata es de contribuir a la mejora de las condiciones materiales de vida de todo ser humano. Satisfacer sus necesidades básicas, al tiempo que se respetan su dignidad, libertad e identidad personal y social.

Este nuevo enfoque sobre el desarrollo empieza a calar hondo en las sociedades occidentales exigiéndose un cambio cualitativo, y no sólo cuantitativo, en la lucha por el desarrollo. En esta línea, De Puelles y Torreblanca (1995: 169) Ilegaron a afirmar que "es un error identificar el crecimiento económico con el desarrollo y de que es necesario no sólo conciliar el crecimiento con el desarrollo social, sino también que el crecimiento económico se traduzca en desarrollo social".

La educación juega aquí un importante papel hasta el punto de convertirse, como defiende Cejudo Córdoba (2006: 369), "en un elemento central para medir el desarrollo humano, sobre todo desde que se vinculara la importancia de la educación al desarrollo económico por medio de la teoría del capital humano (Schultz, 1963; Becker, 1983)".

Con la aparición de la Teoría del Capital Humano la educación ocupa un lugar central a la hora de explicar el crecimiento económico. Autores como Schultz (1963) y Becker (1983) pusieron de manifiesto que el crecimiento económico experimentado por países como Estados Unidos o Japón hacia la primera mitad del siglo XX no era debido solo a los clásicos factores de producción definidos hasta la fecha: Tierra, Trabajo y Capital; sino que entraban en juego otros elementos que incidían en el crecimiento económico. A este cuarto factor lo denominaron "capital humano" entendido, en términos generales, como la capacidad productiva de un individuo que se ve favorecida por una serie de aspectos entre los que destaca la educación.

No obstante, este nuevo enfoque del capital humano concibe a los sujetos-trabajadores como meros factores productivos, es decir, como un elemento más del mecanismo de la producción. Así pues, la educación, sobre todo en estos primeros momentos, es vista como un valor meramente instrumental. Aspecto este muy "peligroso" ya que considera a la persona como una "pieza" más del engranaje productivo. 
Por este motivo, autores como Santarrone y Vittor (2004) critican abiertamente el "uso" que tradicionalmente se ha hecho de la educación por parte de los partidarios de la teoría del capital humano. Estos investigadores critican las ideas calvinistas, de la ética individualista, que subyace a esta visión de la educación exclusivamente como elemento de producción. Centrada en el esfuerzo individual constante, en la ambición por el progreso material y el dinero.

En este sentido, consideramos que es urgente establecer una nueva relación entre "educación y desarrollo" que dé lugar a una nueva "teoría del desarrollo de carácter interdisciplinar". Es preciso conjugar crecimiento económico con desarrollo social y político (Green, 2008; Sen, 1995, 2001, 2010), por lo que la educación no va a tener exclusivamente una función instrumental orientada al crecimiento económico, sino que se buscan también sus efectos sobre la autoestima, autorrealización y la libertad de las personas.

En palabras del Premio Nobel de economía Joseph Stiglitz (2006: 81) "el desarrollo consiste en transformar la vida de las personas y no sólo la economía. Por eso hay que considerar las políticas de educación o empleo a través de la doble óptica de cómo promueven el crecimiento y cómo afectan de manera directa a los individuos. Los economistas se refieren a la educación como capital humano: invertir en la población reporta beneficios, del mismo modo que hacerlo en maquinaria". Este economista señala que la educación tiene otros efectos además de favorecer el crecimiento como son los de "abrir la mente" de los sujetos, dando a entender que es posible el cambio ya que existen otros modos de organizar la producción más equitativos.

Por su parte, el profesor Cabrera (2000) apuntaba que el crecimiento económico puede generar riqueza material, pero que el desarrollo no se puede quedar ahí ya que la riqueza y sus efectos no siempre alcanzan a toda la población (Fukuyama, 2007), por ello el desarrollo debe significar de manera consciente una distribución más equitativa de la riqueza. Todo ser humano tiene derecho a unas condiciones de vida dignas y la educación, como elemento que trasciende la mera formación, instrucción y socialización de la persona, debe contribuir a ello modificando, transformando y mejorando la realidad socioeconómica actual.

Debemos evitar "las discriminaciones invisibles" de las que habla Max Neef (2001) en su obra, orientando la educación a favor de la dignidad humana. Esto supone encontrar vías de desarrollo alternativas al actual modelo económico asentado en principios neoliberales, que obstaculizan el crecimiento personal y social de millones de seres humanos en todo el mundo. Educar para mejorar la calidad de vida de todas las personas sin discriminaciones, evitando con ello los elevados niveles de exclusión social y marginalidad existentes actualmente.

Como señalan Santarrone y Vittor (2004: 16), no podemos seguir siendo meros "consumidores de educación" sumidos y sumisos a un "paradigma de formación que resalta los procesos de observación acrítica, imitación y reproducción-repetición". A lo que Roger (2001: 13) añade que "se educa para moldear, para acoplar. No se educa para pensar ni para capacitar la aptitud crítica". Es necesario dar una salto cualitativo para acercarnos, como comenta este último autor, "a una verdadera sociedad del conocimiento y a una verdadera democracia cognitiva. Necesitamos 
conocer y tener acceso al conocimiento. Una forma de como ciudadanos tener capacidad de poder decidir y hacer algo" (2001: 16).

La educación se presenta así como una pieza clave en la necesaria tarea de generar un desarrollo económico capaz de favorecer a su vez un desarrollo social equitativo (Gobernado, 2009). Ésta debe contribuir al fomento del "capital humano" desde un punto de vista global, y no exclusivamente desde un punto de vista formativo-instructivo. Los sujetos tienen que desarrollar sus competencias técnicas, adquirir conocimientos técnico-profesionales y ponerlos en práctica en el mundo empresarial y productivo para generar valor añadido; pero del mismo modo también deben desarrollar las competencias sociales y personales que les capaciten para la vida en sociedad en sentido amplio. Pues de lo contrario, la educación seguiría al servicio exclusivo de los intereses económicos de "unos pocos" manteniéndose el status quo actual caracterizado por la inequidad y los desequilibrios socioeconómicos.

Pero conseguir esto no es tarea fácil, máxime en un contexto cultural y social caracterizado por un "culto" exacerbado al "dinero", a lo material, al consumo desenfrenado, donde se prima el placer individual y hedonista por encima del bien común y la responsabilidad social. Por todo ello, la sociedad en su conjunto, y los educadores en particular, nos enfrentamos a un gran reto: el de promover un desarrollo social y económico equitativo, respetuoso con el medio ambiente y con las generaciones futuras. Tenemos que reorientar nuestros patrones de crecimiento, así como nuestros modelos de producción en esta dirección, presentándose la educación como elemento estratégico con la que configurar los cambios culturales necesarios para tal fin.

El aspecto cultural cobra especial importancia en este sentido, pues a diferencia de lo que tradicionalmente se ha venido considerando, el desarrollo económico no se explica exclusivamente teniendo en cuenta las clásicas interpretaciones económicas, biológicas y ambientales, sino que, como afirma Galindo (2006a), los factores sociales y culturales son fundamentales a la hora de explicar y justificar el desarrollo de un grupo, sociedad o país. Así pues, se establece una estrecha relación, muy significativa y bidireccional, entre cultura por un lado y desarrollo por el otro.

La cultura entendida en términos generales como el conjunto integrado de costumbres, valores, creencias, símbolos, actitudes, etc., que rigen el comportamiento de los sujetos y/o grupos de una comunidad o región, tiene un peso decisivo en el desarrollo económico. De hecho, cobra cada día más fuerza la idea de que el desarrollo endógeno de un país, grupo o comunidad no se justifica por elementos externos al mismo, sino que son los factores internos o aspectos culturales los que justifican su grado de desarrollo.

Desde esta perspectiva, podemos afirmar que los elementos que definen e integran la cultura de una sociedad constituyen el eje central de su desarrollo. En esta línea, Galindo (2006a) sostiene que se debe invertir más en cultura ya que los países que así lo hacen (véase por ejemplo el caso de algunos países nórdicos como Noruega, Suecia o Finlandia) se desarrollan de manera más rápida a nivel económico, social, educativo, etc., y, por tanto, con mayor equidad que aquellos que no potencian los factores culturales. 
En una línea muy parecida, Marhuenda (2000) destaca la necesidad de promover un auténtico cambio global y cultural para acercarnos al desarrollo y la solidaridad. La educación nos debe ayudar a concienciar sobre las desigualdades entre el Norte y el Sur al tiempo que se fomenta una verdadera acción transformadora. Por ello, se precisa de una educación global, que no se quede en la mera adjetivación y caracterización de las problemáticas sobre el desarrollo, sino una educación para la transformación tanto personal como social. Una educación para la acción, para el cambio real que necesariamente pase por la concienciación y la mejora intencional de la realidad.

Por todo lo dicho, la educación juega un papel fundamental en la consecución del desarrollo. Por lo que no se puede limitar a la mera reproducción y asimilación acrítica de los "valores" que simbolizan y defienden un modelo de crecimiento insostenible, injusto desde el punto de vista social, inequitativo y tremendamente individualista. Es más, se debe enfocar la educación desde una perspectiva más humanista y humanizadora con la que ir configurando nuevos valores y pautas culturales con los que encontrar un equilibrio entre crecimiento económico sostenible y desarrollo social (Sen, 2004, 2007). Tenemos que educar para mejorar la sociedad, para ofrecer oportunidades reales de desarrollo a todo ser humano e ir reduciendo las enormes diferencias socioeconómicas existentes entre unos sujetos y otros; para lo cual se debe producir un importante cambio cultural sobre el que edificar un nuevo modelo de desarrollo socioeconómico más justo y equilibrado.

\section{EdUCACIÓN Y CULTURA EMPRENDEDORA: APROXIMACIÓN A UN MODELO DE DESARROLLO SOCIOECONÓMICO EQUITATIVO}

Teniendo en cuenta todo lo expuesto con anterioridad, nos surgen una serie de preguntas acerca de ¿qué se puede hacer desde el punto de vista educativo para mejorar dicha situación?, ¿cómo podemos favorecer un desarrollo socioeconómico equitativo?, ¿qué estrategias educativas y sociales podemos seguir para reducir las grandes diferencias económicas que estigmatizan a una parte importante de la población? Consideramos que las respuestas a estos interrogantes van en la línea de fomentar la "cultura emprendedora", por medio de acciones educativas, entre colectivos tradicionalmente alejados de los procesos emprendedores.

El actual modelo de crecimiento no da respuesta al "problema del desarrollo". En general, tanto a nivel global o internacional como en el plano nacional, no se observa un crecimiento económico constante en el tiempo, y cuando éste se produce no lo hace por igual a toda la sociedad. Incluso, muchos de los trabajadores de los Ilamados países desarrollados, como es el caso de la Unión Europea, se hallan en situaciones de pobreza (Medialdea y Álvarez, 2005). Todo esto da lugar a grandes desajustes y desequilibrios entre unos miembros de la población y otros. La riqueza se concentra cada vez más en "menos manos" (Yunus, 2008), mientras grandes núcleos de población se ven abocados a la pobreza y la marginalidad. Justificándose de esta forma el desarrollo de valores, normas, creencias, pautas de conducta, etc., en definitiva, una "nueva cultura" (cultura emprendedora) que promueva el equilibrio entre un progreso económico sostenible y el desarrollo social y humano. 
Nos encontramos, pues, ante una serie de retos de la economía mundial, en general, y de la española en particular, entre los que cabe destacar: la necesidad de mejorar la capacidad productiva de buena parte de la humanidad (Requeijo, 2006), y de la sociedad española, con especial incidencia sobre la población joven por tratarse de un colectivo vulnerable en cuanto a paro y desempleo se refiere; al tiempo que se va frenando el impacto negativo que el proceso actual de crecimiento está generando sobre el medio ambiente orientándonos hacia un desarrollo sostenible.

A pesar de que la característica principal del siglo XX, desde el punto de vista económico y teniendo en cuenta la baja productividad de los siglos anteriores, ha sido el gran crecimiento que se ha producido en la economía mundial; lo cierto es que la "globalización económica", como nota particular de este crecimiento, ha provocado un aumento de la pobreza a escala planetaria. El profesor Hernández (2001) sostiene que se ha incrementado el número de pobres en el mundo, inclusive en los países más desarrollados, a causa de una desigual distribución de la renta.

Por lo que en este orden de cosas, son tres los aspectos centrales que justifican la urgencia de promover la "cultura emprendedora" en España:

- El primer elemento es de tipo económico, pues observamos que el modelo de crecimiento actual no es constante, duradero y persistente en el tiempo. Ciclos económicos de crecimiento vienen acompañados de épocas de crisis y recesión económica (Schumpeter, 2002).

- Un segundo aspecto es de orden social. Para Boron (2001) existe una estrecha relación entre "pobreza", por un lado, y "neoliberalismo", por otro lado; entendido este último en términos generales como la política económica que considera negativo, e inclusive contraproducente, una excesiva intervención del Estado en materia de economía defendiendo el libre mercado capitalista como garantía para un mayor crecimiento económico. Este sistema no es equitativo, no es justo desde el punto de vista social y humano, al generar grandes desequilibrios entre unas partes de la población y otras.

- Por último, este patrón de crecimiento basado en el modelo capitalista no es respetuoso con el medio ambiente. Numerosos estudios e investigaciones (Sotelsek y Ahamdanech, 2008) exponen la necesidad de llevar a cabo políticas y acciones concretas para conjugar crecimiento económico y defensa de la naturaleza.

Por lo que, partiendo de los tres aspectos mencionados, proponemos el desarroIlo de la "cultura emprendedora" como estrategia encaminada a encontrar un equilibrio entre crecimiento económico, justicia social y respeto a la naturaleza. Parece pertinente que, en un momento de "incertidumbre" económica, de serios problemas medioambientales y ecológicos, y de graves desequilibrios sociales, se fomente la creación de un sistema de valores ético-emprendedores como el defendido por Galindo (2006b) para que, por medio de la educación, podamos alcanzar el mencionado equilibrio.

La cultura emprendedora aparece como una alternativa de desarrollo y progreso no sólo referido a lo laboral, sino también en el plano social y medioambiental. La necesidad de fomentar la cultura emprendedora viene motivada por razones de 
orden personal, social y económico. En el plano personal, el hecho de emprender, supone un ejercicio de madurez, responsabilidad y autogobierno que se muestra mediante un alto grado de autonomía de los sujetos. Desde el punto de vista social, implica conocimiento, manejo y participación en las redes sociales. Un saber que llevado a la práctica permite la integración y el intercambio social, básicos para el desarrollo comunitario con base en la acción, el compromiso y la equidad. Por último, desde la perspectiva económica consistiría en fomentar prácticas que aumenten el dinamismo de las economías de referencia de los ciudadanos.

Para Crissién (2006) incentivar el autoempleo para consolidar una cultura empresarial es clave para el progreso, de hecho, en expresión del propio autor: "países que han centrado sus modelos económicos, políticas e instituciones en la creación de empresas son países que crecen, que se desarrollan, que generan riqueza y mejoran la calidad de vida de sus pobladores" (2006: 105). Además de relacionar cultura empresarial y progreso, Crissién vincula "desarrollo económico" y "educación empresarial", por lo que se extrae que la educación es el motor de cambio para la construcción de un entorno que genere calidad de vida y desarroIlo (Martínez-Rodríguez, 2009).

En este sentido, podemos decir que existe una estrecha relación entre educación y desarrollo de la cultura emprendedora y, a su vez, entre esta última y el crecimiento económico y social. Así pues, la educación es necesaria para promover la cultura emprendedora, por lo tanto, podemos afirmar que se encuentra en la base del desarrollo económico y social. Corti y Riviezzo (2008: 114) la definen: "como una cultura abierta al cambio y a la búsqueda y explotación de oportunidades para la innovación y el desarrollo", a lo que añaden "el espíritu emprendedor y la creación de empresas se convierten en parte de la estrategia básica de las universidades y la universidad tradicional, docente e investigadora, se transforma en una universidad emprendedora".

La educación, como sostiene Caride (2005), tiene que favorecer el desarrollo comunitario, atendiendo a las necesidades de la comunidad para así transformar la realidad. Una forma de conseguir esto es a través del autoempleo (o cultura emprendedora), como recientemente ha manifestado Yunus (2008), ya que en su opinión, éste es fundamental para el desarrollo de una región. Por lo tanto, si la educación nos ayuda a extender la democracia en una sociedad, para hacerla más justa y equitativa en todos sus ámbitos y dimensiones, no podemos olvidar democratizar también los medios que permiten el desarrollo económico y, por ende, social.

La falta de iniciativa empresarial de los jóvenes es un problema grave al que se enfrenta la sociedad española. Como nos indica Galindo (2005), existe una falta de voluntad y mentalidad de logro entre los jóvenes españoles, lo que pone en evidencia la presencia de valores y creencias laborales (aspectos culturales y psicosociales) que condicionan negativamente la iniciativa empresarial. La educación tiene que contribuir a mejorar dicha realidad, pues de lo contrario, seguiría al servicio de los intereses particulares de unos pocos y, en tal caso, no podríamos seguir hablando de educación, sino a lo sumo de instrucción, o lo que es peor aún, de adoctrinamiento, condicionamiento o socialización en valores y creencias que permiten perpetuar y reproducir el status quo vigente. 
Visto desde esta perspectiva, no parece ya tan arriesgado señalar que el fomento de la cultura emprendedora es una alternativa válida incluso para colectivos y grupos sociales que tradicionalmente han estado desvinculados de las iniciativas empresariales. Puesto que las competencias para emprender se han asociado siempre a las élites sociales, desde el punto de vista intelectual, cultural y económico fundamentalmente.

Se convierte así en un imperativo ético, y un deber educativo, el hecho de mejorar la situación socio-laboral y económica de jóvenes con escasos recursos formativos, culturales y económicos. Por lo que cobra sentido el desarrollo de iniciativas emprendedoras orientadas hacia colectivos históricamente alejados del proceso emprendedor por su condición social y económica. Presentándose, al mismo tiempo, como estrategia de desarrollo humano e interiorizada como proyecto social integrado. Como podemos observar, educación, desarrollo socio-económico, código ético y competencias emprendedoras están íntimamente relacionados, dando como resultado de esta unión la mencionada cultura emprendedora.

Por todas estas razones, una buena política en esta línea debe conjugar: la motivación de los individuos para que asimilen el espíritu empresarial y se doten de las "competencias adecuadas", crear las condiciones propicias para que un proyecto empresarial se convierta en una empresa próspera, y sensibilizar a la sociedad para que valore el éxito empresarial y se reduzca la estigmatización de la quiebra. La educación, en su plano formal, no formal e informal, ocupa un lugar central en todo esto, y debería tener, entre otras muchas funciones, la de poner a los jóvenes en contacto con el espíritu empresarial y darles, junto a sus educadores y formadores, el apoyo que precisan para desarrollar sus competencias emprendedoras.

\section{A MODO DE CONCLUSIÓN}

A lo largo del presente trabajo hemos visto que la noción de "desarrollo" ha tenido una fuerte carga peyorativa desde un punto de vista histórico. Se ha pasado de clasificar a las diferentes sociedades y grupos humanos en función de su "grado de civilización" a hacerlo en base a su "nivel de renta per cápita o Producto Interior Bruto (PIB)", dejando tradicionalmente a un lado aspectos claves como: el grado de alfabetización y educación, la salud, la vivienda, el trabajo digno, la calidad de vida, la seguridad, la estabilidad social y política, la justicia social, etc.

Si bien es cierto que a partir de la Segunda Guerra Mundial se produce un cambio paulatino, al menos a nivel teórico, en la concepción del desarrollo; la realidad nos indica que dicho cambio no ha sido verdaderamente significativo. El número de pobres en el mundo sigue siendo alarmante, inclusive en los países denominados a sí mismos "desarrollados". La falta de agua potable y de alimentos básicos, por no mencionar otros aspectos, es una nota característica en numerosos grupos humanos en pleno siglo XXI, mientras tanto un grupo más limitado de sujetos se "permiten el lujo" de hacer un uso irresponsable e insostenible de los recursos naturales.

En este contexto no se puede hablar de un auténtico desarrollo, si entendemos éste como mejora de las condiciones de vida de la persona en todos sus ámbitos. Así pues, debemos pasar de las palabras a los hechos y concienciarnos de la nece- 
sidad de reorientar y dirigir el desarrollo de manera consciente hacia una distribución más equitativa de la riqueza. Todo ser humano tiene derecho a unas condiciones de vida dignas y la educación, como elemento que trasciende la mera formación, instrucción y socialización de la persona, debe contribuir a ello modificando, transformando y mejorando la realidad socioeconómica actual.

Por este motivo, nos hemos planteado como objetivo prioritario para alcanzar el desarrollo el de sensibilizar acerca de la necesidad de fomentar y consolidar la cultura emprendedora. En una situación económica y laboral caracterizada por la incertidumbre, en la que parece, no se puede garantizar un crecimiento económico constante, y en la que encontramos altas tasas de desempleo asociadas a un alto grado de inestabilidad laboral, parece justificada la adopción de medidas encaminadas a "aliviar" los problemas derivados de la falta de empleo. El fomento de la cultura emprendedora, por medio de planteamientos y acciones educativas, se presenta como estrategia de intervención socioeducativa orientada al desarrollo y encaminada a minimizar los daños que el actual modelo de crecimiento está ocasionando tanto a nivel social como medioambiental.

Desde esta perspectiva, las competencias emprendedoras no sólo deben ayudar a los sujetos a desarrollar con éxito una iniciativa empresarial, sino también a cultivar valores y prácticas sociales asentadas en principios democráticos. Por ello, compartimos la opinión del profesor Pablo Galindo (2006b: 132) al considerar que "la adopción de rasgos éticos obliga a adoptar comportamientos emprendedores que beneficiarán a los individuos u organizaciones que los presentan."

Por todo lo expuesto, podemos concluir diciendo que con el fomento de la cultura emprendedora queremos atender no sólo al crecimiento económico, que por otro lado está justificado siempre y cuando sea un crecimiento sostenible, justo y respetuoso con los seres humanos y la naturaleza; sino también incidir y fomentar el desarrollo personal y social. La formación de los trabajadores para el desarrollo de sus competencias no se puede, ni debe, subordinar a la mejora de la economía como si esta fuera el objetivo prioritario de la educación de todos los ciudadanos. El fomento de las competencias emprendedoras por medio de la educación debe ayudar, por un lado, a potenciar la creatividad y la iniciativa para generar una cultura emprendedora, y por otro lado, desarrollar las capacidades y potencialidades humanas necesarias para una convivencia democrática.

\section{REFERENCIAS BIBLIOGRÁFICAS}

AZQUETA, D. y SOTELSEK, D. (2007). La Economía del Desarrollo: una perspectiva histórica. Ekonomiaz: Revista Vasca de Economía, 64, 14-35.

BECKER, G. S. (1983). El capital humano: un análisis teórico y empírico referido fundamentalmente a la educación. Madrid: Alianza.

BORON, A. (2001). Pobreza y neoliberalismo. Cuadernos de Pedagogía, 308, 18-23.

BRUNET, I. y BÖCKER, R. (2007). Desarrollo, industria y empresa. Madrid: Tecnos. CABRERA, L. J. (2000). Educación y Desarrollo. Revista de Educación, 322, 211-245.

CARIDE, J. A. (2005). La Animación Sociocultural y el Desarrollo Comunitario como educación social. Revista de Educación, 336, 73-88. 
CEJUDO, R. (2006). Desarrollo humano y capacidades. Aplicaciones de la teoría de las capacidades de Amartya Sen a la educación. Revista Española de Pedagogía, 234 (64), 365-380.

CORTI, E. y RIVIEZZO, A. (2008). Hacia la universidad emprendedora: un análisis del compromiso de las universidades italianas en el desarrollo económico y social. Economía industrial, 368, 113-124.

CRISSIÉN, J. (2006). Espíritu empresarial como estrategia de competitividad y desarrollo económico. Revista EAN, 57, 103-108.

DE PUELLES, M. y TORREBLNACA, J. I. (1995). Educación, Desarrollo y Equidad Social. Revista Iberoamericana de Educación, 9, 165-189.

FUKUYAMA, F. (2007). La ingeniería social y el problema del desarrollo. Barcelona: Ediciones B.

GALINDO, P. (2005). Cultura Emprendedora y dinámica sociolaboral. Estado de la cuestión. En J. ROMAY y R. GARCÍA (Eds.), Psicología social y problemas sociales (4): psicología de las organizaciones, del trabajo y recursos humanos y de la salud (pp. 419-424). Madrid: Biblioteca Nueva.

GALINDO, P. (2006a). Las complejidades del desarrollo socioeconómico en el caso de Andalucía. Revista de Estudios Andaluces, 26, 13-35.

GALINDO, P. (2006b). Cultura Ético-Emprendedora (E2) y desarrollo de competencias transversales clave para la inserción sociolaboral de los universitarios. Revista de Educación de la Universidad de Granada, 19, 129-146.

GEORGE, H. (2008). Progreso y miseria: del origen de las crisis industriales y del aumento de la miseria. Granada: Comares.

GOBERNADO, R. (2009). Educación formal y desarrollo: Andalucía y Cataluña como ejemplos. Revista Española de Pedagogía, 242 (67), 5-26.

GREEN, D. (2008). De la pobreza al poder: cómo pueden cambiar el mundo ciudadanos activos y estados eficientes. Madrid: Oxfam Internacional.

HERNÁNDEZ, L. (2001). Los organismos económicos internacionales y la pobreza. Boletín Económico de ICE, 2710, 33-45.

MARCUSE, H. (1984). La agresividad en la sociedad industrial avanzada y otros ensayos. Madrid: Alianza.

MARHUENDA, F. (2000). Solidaridad y educación para el desarrollo. Comunicar, 15, 93-98.

MARTÍNEZ-RODRÍGUEZ, F. M. (2009). Género, cultura emprendedora y educación: un estudio descriptivo. Revista de Ciencias de la Educación, 217, 59-79.

MAX NEEF, M. (2001). Las discriminaciones invisibles. En R. DÍEZ HOCHLEITNER (Coord.), Aprender para el futuro: educación a favor de la dignidad humana (pp. 95-98). Madrid: Fundación Santillana.

MEDIALDEA, B. y ÁLVAREZ, N. (2005). Ajuste neoliberal y pobreza salarial: los "working poor" en la Unión Europea. Viento Sur, 82, 56-64.

NAVARRO, V. (2008). Propuestas a la crisis: evitando la segunda Gran Depresión. Temas para el debate, 167, 71-74.

REQUEIJO, J. (2006). Economía mundial. Madrid: MacGra-Hill. 
ROGER CIURANA, E. (2001). Educación y desarrollo humano. Tabanque: Revista Pedagógica, 16, 9-18.

SAMUELSON, P. A. y NORDHAUS, W. D. (2006). Economía. Madrid: McGraw-Hill.

SANTARRONE, F. y VITTOR, A. (2004). La neo educación liberal: una visión general acerca de las ideas neoliberales sobre educación. Aula Abierta, 83, 3-20.

SCHUlTZ, T. W. (1963). The Economic Value of Education. New York: Columbia University Press.

SCHUMPETER, J. A. (2002). Ciclos económicos: análisis teórico, histórico y estadístico del proceso capitalista. Zaragoza: Prensas Universitarias de Zaragoza.

SEN, A. (1995). Nueva economía del bienestar: escritos seleccionados. Valencia: Universidad de Valencia.

SEN, A. (2001). Sobre ética y economía. Madrid: Alianza Editorial.

SEN, A. (2004). Nuevo examen de la desigualdad. Madrid: Alianza Editorial.

SEN, A. (2010). La idea de la justicia. Madrid: Taurus.

SOTELSEK, D. y AHAMDANECH, I. (2008). Reflexiones sobre el crecimiento, el medio ambiente y la pobreza. Economía Industrial, 367, 153-166.

STIGLITZ, J. E. (2006). Cómo hacer que funcione la globalización. Madrid: Taurus.

TODARO, M. P. (1982). Economía para un mundo en desarrollo: introducción a los principios, problemas y políticas para el desarrollo. México: Fondo de Cultura Económica.

VARELA, M. y VARELA, F. (2002). Las instituciones internacionales ante la globalización. ICE: Revista de Economía, 799, 13-30.

YUNUS, M. (2008). Un mundo sin pobreza: las empresas sociales y el futuro del capitalismo. Barcelona: Paidós. 